\title{
Adolescent abuse in a community sample in Beni Suef, Egypt: prevalence and risk factors
}

\author{
Z.E.M. Afifi, ${ }^{1}$ M.I. El-Lawindi, ${ }^{1}$ S.A. Ahmed ${ }^{2}$ and W.W. Basily ${ }^{3}$
}

$$
\begin{aligned}
& \text { انتهاك المراهقين في عينة من الجمتمع في بني سويف، مصر : معدل الانتشار وعوامل الاختطار }
\end{aligned}
$$

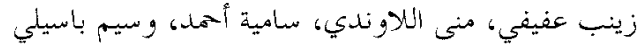

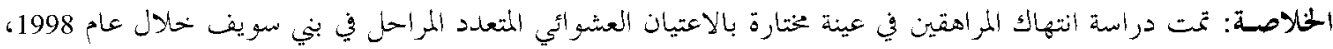

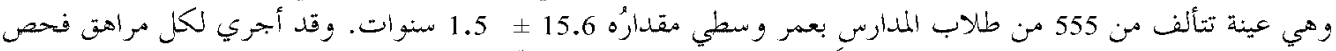

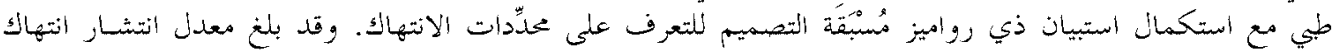

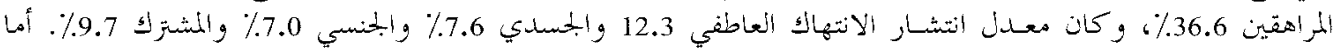

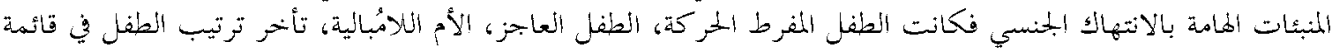

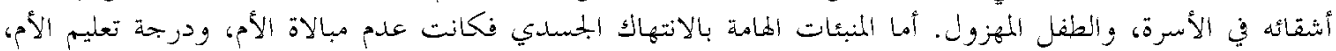

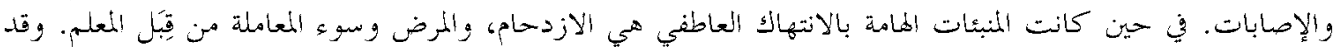

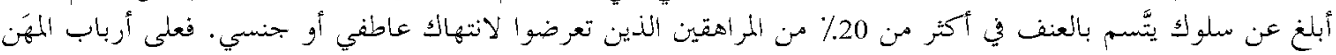

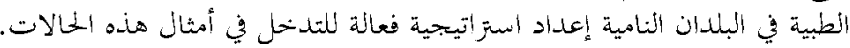

ABSTRACT Adolescent abuse was studied in 555 school students (mean age $15.6 \pm 1.5$ years) selected by multistage random sampling in Beni Suef in 1998. Each student received a general physical examination and a pre-coded questionnaire to identify determinants of abuse. Prevalence of abuse was $36.6 \%$. Emotional, physical, sexual and combined abuse prevalence was $12.3 \%, 7.6 \%, 7.0 \%$ and $9.7 \%$ respectively. Significant predictors of sexual abuse were hyperactive child, disabled child, disinterested mother, low birth order child or wasted child. For physical abuse, significant predictors were maternal disinterest, maternal education and injuries. Significant predictors of emotional abuse were overcrowding, disease and mistreatment by a teacher. Violent behaviour was reported for more than $20 \%$ of the emotionally and the sexually abused.

La maltraitance des adolescents dans un échantillon communautaire à Beni Suef (Egypte) : prévalence et facteurs de risque

RESUME La maltraitance des adolescents a été étudiée chez 555 lycéens (âge moyen 15,6 $\pm 1,5$ ans) sélectionnés par échantillonnage aléatoire à plusieurs niveaux à Beni Suef durant l'année 1998. Chaque adolescent a subi un examen physique général et a reçu un questionnaire précodé pour identifier les déterminants de la maltraitance. La prévalence de la maltraitance des adolescents était de 36,6\%. La prévalence de la violence psychologique, physique, sexuelle et multiple était de $12,3 \%, 7,6 \%, 7,0 \%$ et $9,7 \%$ respectivement. Les facteurs prédictifs significatifs de la violence sexuelle étaient l'hyperactivité de l'enfant, le handicap de l'enfant, le désintérêt de la mère, le rang de naissance de l'enfant ou l'émaciation. Pour la violence physique, les facteurs prédictifs significatifs étaient le désintérêt de la mère, l'instruction de la mère et les traumatismes. Les facteurs prédictifs significatifs de la violence psychologique étaient la promiscuité, la maladie et les mauvais traitements infligés par un enseignant. Un comportement violent était signalé pour plus de $20 \%$ des enfants ayant subi une violence psychologique et sexuelle.

${ }^{1}$ Department of Public Health; ' 2 Department of Psychiatry, Faculty of Medicine, Kasr El-Aini University, Cairo, Egypt.

${ }^{3}$ Ministry of Health and Population, Cairo, Egypt.

Received: 04/04/02; accepted: 01/10/02

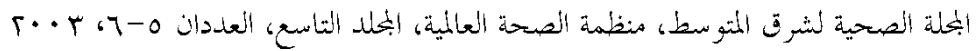




\section{Introduction}

Children have been abused throughout human history, but only recently has child abuse come to be seen as a major social problem and as a primary cause of personal problems [1]. Child abuse has been defined as any maltreatment of a child or an adolescent by a guardian or caretaker [2]. More recently, it has also been defined as any injury, sexual abuse, malnutrition, physical or emotional suffering or even neglect of a child under 18 years of age inflicted by a person responsible for that child's welfare [3]. Abused children are prone to psychiatric problems, medical ailments, chronic fatigue, suicidal tendencies, delinquency and low IQ [4-8]. They may develop serious sequelae that can lead to permanent disability or even death [9].

Child abuse is a major paediatric problem in many countries. In 1993, approximately 3 million reports of child abuse and neglect were made to child protective services agencies in the United States of America; $35 \%$ of these cases were confirmed [10]. Incidence increased to 11.8/ 1000 in 1999 [11]. In a Canadian study of reported child abuse and neglect, the annual incidence rate was 21.52 investigations of child abuse and neglect per 1000 children; $45 \%$ of those were substantiated, $22 \%$ remained suspected but unconfirmed and $33 \%$ were unsubstantiated [12]. Further evidence was provided by a 1997 British survey in which it was estimated that each year at least 1 child per 1000 children under the age of 4 years suffered physical abuse [13].

In developing countries it is likely that most doctors working with children see cases of physical abuse and that these are just a small portion of the total. Studies from Nigeria, South Africa and the Caribbean island of Dominica indicate the extent of the problem [14-16].
In Egypt, few studies have investigated the problem of child abuse. In most of these studies, the cases were from emergency or clinical departments, social welfare or criminal records or autopsies [8,9,17-20]. In 1994 and 1999, child abuse among Egyptian primary-school children was studied, but no data were collected regarding the prevalence of abuse among older preparatory-school and secondaryschool children $[21,22]$. Therefore, in our study, we investigated child abuse in an Egyptian rural community to identify underlying risk factors and to detect the physical and emotional consequences of child abuse.

\section{Methods}

During 1998, a sample of 555 adolescents from preparatory schools and secondary schools in Ihnasya El-Medina, Beni Suef Governorate, Egypt, were selected by random cluster sampling for our study. At that time, child abuse prevalence data were available only for primary-school children $[4,21]$. From these data we calculated the overall prevalence of abuse for primaryschool children to be $30 \%$. As the prevalence of abuse is lower among older children and decreases with age, we assumed that this figure would be halved among our older students [11-13,23]. Accordingly the size of the sample was calculated using Epi-info software, version 5, assuming $15 \%$ expected frequency with 95\% confidence interval. The sampling fraction was $6 \%$ of the preparatory-school and secondary-school child population. Each of the 7 schools in Ihnasya-3 preparatory and 4 secondary (1 general, 1 industrial, 1 technical and 1 trade) -represented a cluster from which 1 or 2 classes were randomly selected according to the re- 
quired number in proportion to the student population.

A pre-coded questionnaire was prepared in Arabic and tested on 50 students before its use in the survey. It included questions on the presence or absence of different types of abuse, personal data about the children and their parents, factors known to be associated with child abuse and possible outcomes of abuse. We collected child data that included age, sex, school performance, perceived hyperactivity, helplessness (i.e. weakness, incapability and unresponsiveness), presence of disease, disability, living away from the family, sharing the bed with others or having problems with parents. We also collected data about parental behaviours associated with abuse and related to rearing the child in health and to dealing with the other parental partner and about mistreatment by teachers. These included quarrelling, fighting, physical or psychological cruelty, rejection, terrorizing and disinterest. Familial relations, problems and sociodemographic factors such as income, item or property ownership, type of family, residence and degree of household crowding were also recorded.

In each of the selected classes we explained the rationale of the study and emphasized confidentiality in handling collected data. The questionnaires were then distributed for the students to answer. Student consent was taken and the adolescents were asked to inform their parents. No one refused to participate. Each student was examined generally including body systems, blood pressure, signs of malnutrition, weight and height and for signs of previous (scars or deformities) or recent physical abuse (bruises, burns or scalds). A male physician who was known in the community examined the children and was assisted by a female nurse or social worker when examining girls and by a male nurse or social worker when examining boys. Questionnaires were checked for completeness so that nothing was excluded. The data were analysed using SPSS software, version 9.0.

A student was considered emotionally abused if he or she reported 5 or more of these 10 items:

- feeling of low value;

- loneliness;

- rejection at home;

- perceptions that the family structure is wrong;

- parents do not respond to needs;

- no participation in decision-making;

- perceptions of being obliged to give up rights for a sibling;

- parental preferential prejudice towards sibling(s);

- hurt from improper treatment;

- neglected when sick.

Students were considered physically abused if they reported being beaten to the point of bruising, wounding, fractures or worse or burns inflicted by an adult caregiver. Their reports were confirmed by examination. Those reporting abuse in the absence of physical signs and those who had signs suggestive of abuse but who denied the event were not considered physically abused.

A student was considered sexually abused if his or her sex organs were touched by anyone of the other or same sex for reasons other than health or medical purposes.

For the purposes of our study, we did not distinguish between signs of abuse and symptoms that might be similar to clinical depression, mental illness or other problems. Degree or intensity of each item was also not distinguished. Our study also did

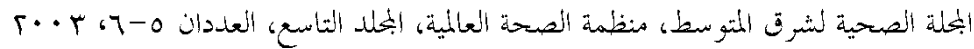


not distinguish between previous and recent episodes of abuse.

Descriptive statistics were calculated for all variables. The presence and significance of association between abuse (qualitative nominal variable indicating non-abuse and 4 categories of abuse-emotional, physical, sexual and combined) and the determining factors were assessed by chisquared distribution or analysis of variance. The odds ratios (OR) and their significance were calculated for each of the independent variables with the 4 types of abuse versus no abuse. Significant variables were used as independent variables in subsequent analysis. A logistic regression model was fitted for each type of abuse and all independent variables together. We included 2 quantitative covariates, namely birth order and degree of household crowding. The best model that explained the relationship between the dependent and significant independent variables was determined by forward conditional stepwise selection.

\section{Results}

\section{Sample characteristics}

The age of the studied group was 12-18 years with a mean of $15.6 \pm 1.5$ years. The median birth order was 3 . The male/female ratio was 1.7 . More than $50 \%$ of the children felt accepted and loved by their families. Approximately one-quarter of students had learning difficulties, were perceived as hyperactive, had lived away from the family for some time, were sharing a bed with others or were maltreated by teachers. Blood pressure measurements were within normal ranges. The average systolic and diastolic blood pressures were $124.9 \pm 8.9$ and $63.0 \pm 5.4 \mathrm{mmHg}$ respectively.

According to the World Health Organization weight/age classification scheme, $95.9 \%$ were well nourished (-2 to $+2 \mathrm{Z}$ - scores), $2.9 \%$ were wasted $(<-2 \quad Z$ scores) and $1.2 \%$ were overweight ( $>2 \mathrm{Z}$ scores) [24]. The prevalence of stunting (height/age $<-2$ Z-scores) was $17.6 \%$. Of all students, $16.5 \%$ reported having a chronic disease. On examination $10.5 \%$ of them showed positive respiratory, cardiac and gastrointestinal tract findings. Furthermore, 68 students had physical disabilities including partial paralysis (4), amputated limbs (4), epilepsy (3) and speech impairments (11), or visual (46) or hearing problems (10). Manifestations of past or recent physical abuse were obvious by examination for $14.6 \%$ and included burns (5.4\%), bruises $(3.6 \%)$, scratches $(1.8 \%)$, bite marks $(0.4 \%)$ and scars (3.4\%). Somatic manifestations attributable to causes other than abuse were not included. The main criteria were the presence of signs confirmed by student report.

Six students who did not report abuse had physical signs suggestive of abuse. We re-questioned them, but they denied abuse and for the purposes of this study were considered non-abused.

The mean age of fathers and mothers was $47.9 \pm 11.0$ years and $38.9 \pm 7.3$ years respectively. Illiteracy and low levels of education (primary schooling or ability to read and write only) were prevalent among parents. The illiteracy rate was $30.1 \%$ for fathers and $63.3 \%$ for mothers. Low levels of education characterized $41.0 \%$ of fathers and $24.1 \%$ of mothers. Most fathers were labourers (60.5\%) or employees (32.0\%) while most mothers were housewives (91.4\%). Most parents (83.2\%) had a reward system for their children. Troubles existed between parents in $9.7 \%$ of cases. These included quarrels (4.5\%), alienation $(2.2 \%)$, divorce $(1.6 \%)$, beating $(0.9 \%)$ and other problems $(0.5 \%)$. Conflicts existed between parents and children as well: $11 \%$ of the children reported having problems in their families and $8.4 \%$ had 
parents who quarrelled with them. Students were asked only to report the presence or absence of conflict; intensity of conflict was not determined.

Most children (82.1\%) belonged to nuclear families that lived in single-family homes. Few families changed their residences frequently (5\%). Family size was large with a mean of $8.3 \pm 2.7$ persons. Family income was considered adequate or more than adequate by $66.5 \%$ of the students. The number of siblings was large with a mean value of $5.0 \pm 2.1$. The average number of unschooled siblings of school age or older was $2.5 \pm 1.4$. A family member who smoked was present in $67.3 \%$ of households and a family member who drank alcohol was present in 5\%.

\section{Overall prevalence of child abuse}

Table 1 shows the prevalence of abuse among the adolescents. The overall prevalence of abuse was $36.6 \%$. Approximately one-quarter experienced only one form of abuse. Combined abuse (2 or 3 forms) was experienced by $9.7 \%$. Emotional abuse was most prevalent (12.3\%), followed by physical abuse (7.6\%) and sexual abuse (7\%). Common combinations were physical and emotional abuse $(4.7 \%)$ and sexual and emotional abuse (3.8\%). Emotional abuse alone or combined with other forms affected $21.3 \%$ of the students. Both physical and sexual abuse, either alone or combined with others affected $13.5 \%$ and $12.1 \%$ of the children respectively.

\section{Risk factors}

Analysis of variance showed no significant difference between the 5 groups of adolescents (emotional, physical, sexual, combined and no abuse) in any of the measured continuous variables (i.e. weight, height, age of child, birth order, age of parents, number of rooms, family size and number of siblings). Table 2 shows the ORs associ-
Table 1 Distribution of cases according to the prevalence of the form of abuse

\begin{tabular}{lrr}
\hline Form of abuse & $\begin{array}{c}\text { No. of } \\
\text { students }\end{array}$ & \% \\
\hline Emotional abuse & 68 & 12.3 \\
Physical abuse & 42 & 7.6 \\
Sexual abuse & 39 & 7.0 \\
Emotional and physical abuse & 26 & 4.7 \\
Emotional and sexual abuse & 21 & 3.8 \\
Physical and sexual abuse & 4 & 0.7 \\
Physical, emotional and sexual & & \\
$\quad$ abuse & 3 & 0.5 \\
No abuse & 352 & 63.4 \\
Total & 555 & 100.0 \\
\hline
\end{tabular}

ated with each type of abuse compared with no abuse. Of the studied child factors, living away from the family increased the odds of all forms of abuse 2.7 times or more. Injury signs were more common in cases of physical, sexual and combined abuse. Maltreatment of the student by the teacher, on the other hand, was the most significant predictor of emotional abuse. Helplessness and having a disease or learning disabilities significantly increased the odds of all but sexual abuse.

Except for mother's work, all parental factors significantly affected the odds of one or more form of abuse. Predominance of the father and father's bad attitude towards the mother significantly affected only the odds of combined abuse. The presence of smoking in the family increased the odds of physical abuse $(P<$ $0.05)$. All other familial factors increased significantly the odds of emotional and combined abuse. In our univariate analysis, no tested socioeconomic variables, e.g. residence, income and type of family, af-

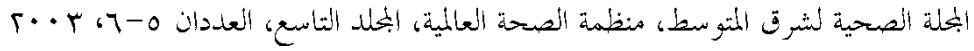




\begin{tabular}{|c|c|c|c|c|}
\hline Risk factors & Emotional & Physical & Sexual & Combined \\
\hline \multicolumn{5}{|l|}{ Child factors } \\
\hline Sex (male) & 1.4 & 1.5 & $2.3^{*}$ & 1.2 \\
\hline Helplessness & $3.3^{* *}$ & $2.9^{*}$ & 2.4 & $3.8^{\star \star}$ \\
\hline Hyperactivity & $2.1^{*}$ & 1.4 & $3.1^{* \star}$ & $2.1^{*}$ \\
\hline Wasting & 2.6 & 3.0 & $6.6^{\star \star}$ & 0.01 \\
\hline Having disease & $2.9^{\star *}$ & $2.9^{\star}$ & 0.6 & $3.3^{\star \star}$ \\
\hline Having disability & 1.4 & $2.6^{*}$ & 1.5 & 1.6 \\
\hline Having learning difficulty & $3.4^{* *}$ & $2.4^{*}$ & 1.8 & $2.6^{\star \star}$ \\
\hline Living away from family & $2.7^{\star \star}$ & $4.0^{\star \star}$ & $3.0^{\star *}$ & $2.9^{\star \star}$ \\
\hline Sharing bed with others & 1.6 & 1.1 & 1.6 & $3.1^{\star *}$ \\
\hline Injury signs & 1.6 & $145.4^{* *}$ & $1.8^{*}$ & $29.5^{\star \star}$ \\
\hline Mistreated by teacher & $4.0^{\star *}$ & 1.3 & 1.4 & $3.3^{\star *}$ \\
\hline \multicolumn{5}{|l|}{ Parental factors } \\
\hline \multicolumn{5}{|l|}{ Mother } \\
\hline Education (high) & 1.6 & $6.4^{*}$ & 0.0 & 2.0 \\
\hline Work & 1.6 & 1.2 & 2.0 & 0.3 \\
\hline Disease & 2.0 & 1.7 & $2.5^{\star}$ & $6.9^{\star \star}$ \\
\hline Cruelty & 2.3 & 1.5 & 0.4 & $3.4^{* \star}$ \\
\hline Disinterest & $3.0^{\star}$ & 2.2 & $5.7^{\star \star}$ & $5.3^{\star \star}$ \\
\hline \multicolumn{5}{|l|}{ Father } \\
\hline Education (middle) & 0.8 & $2.3^{*}$ & 1.4 & 0.5 \\
\hline Disease & $2.1^{*}$ & $2.2^{\star}$ & 1.9 & $4.9^{\star \star}$ \\
\hline Cruelty & 1.5 & 1.2 & 0.5 & $0.5^{\star}$ \\
\hline Disinterest & 0.8 & 1.4 & $4.0^{\star \star}$ & 2.0 \\
\hline Prison & 2.6 & 1.3 & $4.8^{\star \star}$ & $3.2^{*}$ \\
\hline \multicolumn{5}{|l|}{ Familial factors } \\
\hline Predominance (father) & 0.8 & 1.6 & 1.2 & $0.5^{\star}$ \\
\hline Father has bad attitude & 21 & O & 10 & $31^{*}$ \\
\hline Parents quarrel with child & $3.3^{*}$ & 1.3 & 1.1 & $3.4^{\star \star}$ \\
\hline Trouble between parents & $3.3^{\star *}$ & 1.8 & 1.9 & $6.5^{\star \star}$ \\
\hline Problems in the family & $2.6^{\star \star}$ & 1.8 & 1.4 & $2.3^{*}$ \\
\hline Smoking & 1.3 & $2.7^{\star}$ & 1.0 & 1.3 \\
\hline Reward system & $0.2^{* *}$ & 0.9 & 0.3 & $0.2^{\star \star}$ \\
\hline
\end{tabular}

${ }^{*} \mathrm{P}<0.05,{ }^{* * \mathrm{P}}<0.01$.

fected the occurrence of abuse significantly.

Table 3 shows the final logistic regression models fitted with all significant variables using a forward stepwise selection procedure. Conditioning on all other variables, the significant predictors of emotional abuse were crowding in the house, sickness of the child and teacher maltreatment; the estimated odds of abuse $(\operatorname{Exp}(\beta)$ 
Table 3 Conditional odds ratios associated with each type of abuse (forward conditional stepwise selection)

\begin{tabular}{|c|c|c|c|c|}
\hline $\begin{array}{l}\text { Form of abuse } \\
\text { (Item in model) }\end{array}$ & $\beta$ & Significance & $\operatorname{Exp}(\beta)$ & $\begin{array}{l}95 \% \mathrm{Cl} \text { for } \\
\operatorname{Exp}(\beta)\end{array}$ \\
\hline \multicolumn{5}{|l|}{ Emotional abuse } \\
\hline Crowding & 0.5 & 0.028 & 1.7 & $1.1-2.7$ \\
\hline Sickness & 1.5 & 0.025 & 4.7 & $1.2-17.9$ \\
\hline Teacher maltreatment & 2.4 & 0.001 & 10.8 & $3.3-35.1$ \\
\hline \multicolumn{5}{|l|}{ Physical abuse } \\
\hline Disinterested mother & 3.6 & 0.008 & 36.9 & $2.6-527.0$ \\
\hline Education of mother & 3.1 & 0.019 & 22.3 & $1.7-295.1$ \\
\hline Injury signs & 6.5 & 0.000 & 688.3 & $40.8-11614.1$ \\
\hline \multicolumn{5}{|l|}{ Sexual abuse } \\
\hline Hyperactivity & & 0.009 & & \\
\hline Perceived hyperactivitya & 2.5 & 0.002 & 11.8 & $2.5-57.8$ \\
\hline Unknown hyperactivity ${ }^{\mathrm{b}}$ & -1.3 & 0.199 & 0.3 & $0.0-2.0$ \\
\hline Disability & 2.2 & 0.011 & 9.1 & $1.6-50.6$ \\
\hline Disinterested mother & 3.9 & 0.000 & 48.6 & $6.5-363.9$ \\
\hline Birth order & -0.5 & 0.013 & 0.6 & $0.4-0.9$ \\
\hline Wasting & 6.2 & 0.002 & 481.8 & $10.7-21734.1$ \\
\hline \multicolumn{5}{|l|}{ Combined abuse } \\
\hline $\begin{array}{l}\text { Parents quarrel with } \\
\text { child }\end{array}$ & 2.9 & 0.010 & 18.0 & $2.0-164.3$ \\
\hline Sick father & 3.4 & 0.021 & 30.6 & $1.7-558.6$ \\
\hline Sick mother & 4.3 & 0.006 & 71.6 & $3.3-1546.1$ \\
\hline Predominance of father & -5.7 & 0.003 & 0.0 & $0.0-0.01$ \\
\hline Cruel mother & 4.9 & 0.053 & 135.8 & $0.9-19760.9$ \\
\hline Problems in family & 4.0 & 0.004 & 53.7 & $3.6-791.5$ \\
\hline Birth order & -1.6 & 0.012 & 0.2 & $0.1-0.7$ \\
\hline Teacher maltreatment & 3.7 & 0.012 & 40.3 & $2.3-713.5$ \\
\hline Injury signs & 4.9 & 0.002 & 136.2 & $5.8-3202.1$ \\
\hline
\end{tabular}

${ }^{a}$ Perceived hyperactivity: children who reported that others perceived them as hyperactive.

'Unknown hyperactivity: children who did not know if others perceived them as hyperactive.

associated with them were 10.8, 4.7 and 1.7 respectively. The best predictors of physical abuse were maternal disinterest, maternal education and the presence of injury signs on the student's body. The odds of physical abuse were more than 20 times higher in association with these 3 factors. The significant predictors of sexual abuse were hyperactive child, disabled child, disinterested mother, low birth order child or wasted child. Combined abuse had more parental predictors than any other form.

\section{Outcome sequelae}

Aggressive and abusive behaviour and the adoption of habits such as smoking and al-

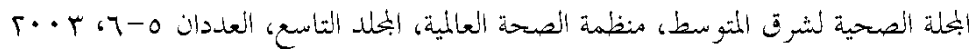


cohol intake were more prevalent among abused children (Table 4). The observed overall difference was statistically significant $(P<0.01)$ for aggressive and abusive behaviour only. Violent behaviour was reported for more than $20 \%$ of the emotionally and sexually abused. Attention seeking behaviours were most common (59.3\%) in the combined abuse group. Abusive behaviours were more common among those in the sexual abuse and combined abuse groups. More than $20 \%$ of the 2 groups reported touching or staring at the genitalia of the other or the same sex.

When the odds of such behaviour were calculated for each type of abuse versus no abuse, emotional abuse increased significantly the odds of violence and staring at the genitalia of the other or the same sex (ORs $=4.1,3.3$ and 6.7 respectively). Physical abuse did not significantly affect the odds of practising any of these behaviours. Sexual abuse significantly increased the odds of violence and all 4 abusive behaviours (ORs = 3.4, 6.5, 4.6, 4.4 and 20.3 respectively; Table 4). Combined abuse increased the odds of all behaviour patterns. The odds were significant in association with attempting to attract attention, all 4 abusive behaviours and drinking and smoking (ORs = 2.4, 4.8, 7.2, 5.4, 19.8 and 2.9 respectively).

\section{Discussion}

Abuse is widely prevalent among preparatory-school and secondary-school children in Ihnasya. Because the students in our study were selected randomly to represent the adolescent student mix, the results may be generalized to adolescent schoolchildren

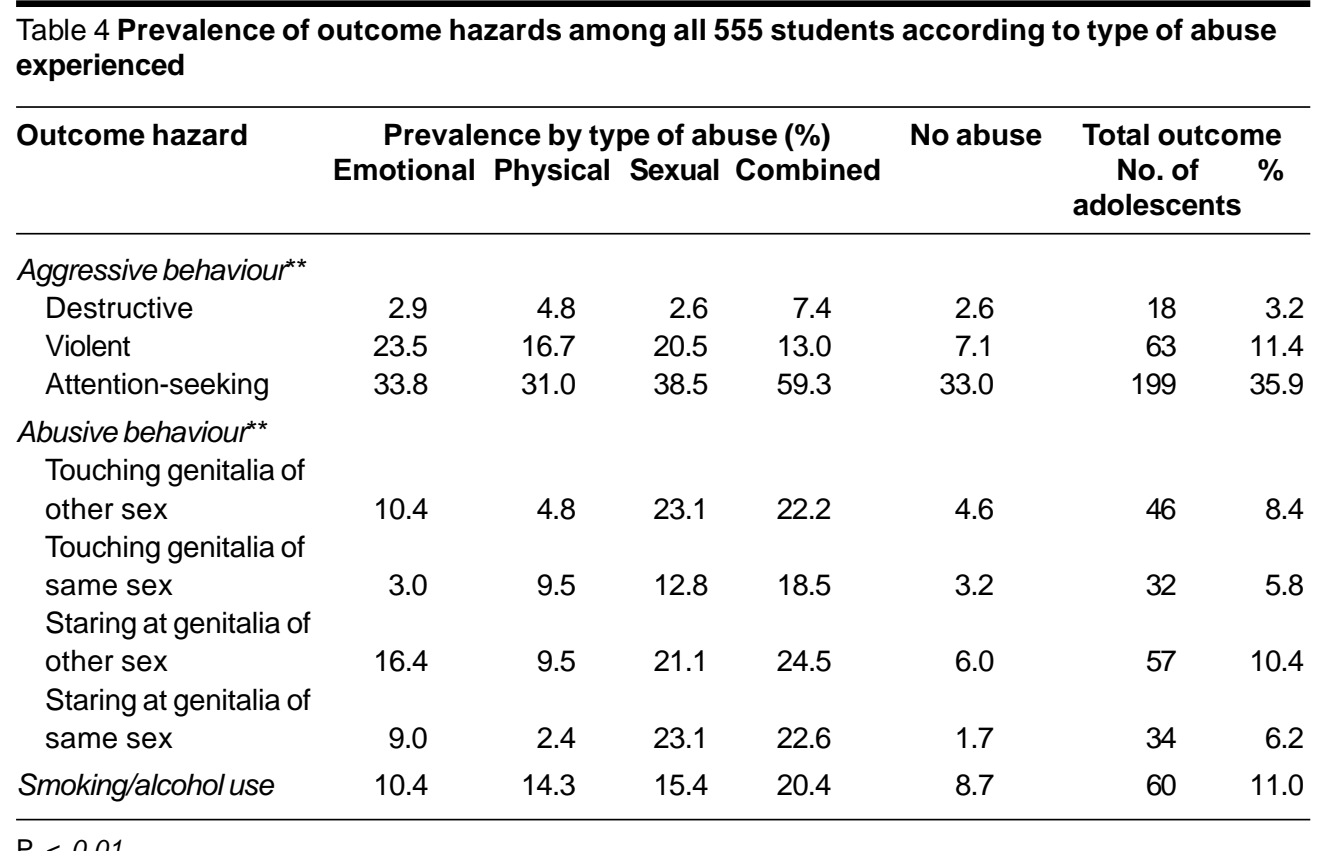

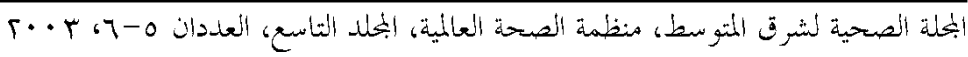


in Upper Egypt and those living in similar conditions. Beni Suef is a district that is mostly rural, overcrowded and with service availability similar to many other areas in Egypt. The overall prevalence of abuse was $36.6 \%$, which is higher than other reports of Egyptian preschool children and primary-school children $[18,21]$. Some differences can be attributed to the definition of abuse in each study and to under-reporting as the data in the other 2 studies were gathered by questionnaires completed by parents. Some parents might not perceive physical punishment triggered by the child's misconduct or belittling the child as abuse [25,26]. Moreover, parents might not be aware of the occurrence of sexual abuse or might refrain from mentioning it.

Abdel-Rahman reported a much lower overall incidence of abuse (5.7\% of 13689 reported cases) in Cairo, Giza and Qalyubiya areas [20]. The prevalence of abuse among reported crimes does not reflect the prevalence in a community, however, as they include sexual and physical but not emotional assaults. There is also the problem of under-reporting [25]. Sexual abuse is often hidden within families and may not be revealed until the victim speaks of it later in life [27].

Our observed rates were lower than those reported in Egypt and abroad by mothers having at least 1 child less than 18 years of age $[13,26,28]$. In the former, the study of abuse was based on the behaviour and perceptions of the mother rather than of the child, and abuse was defined differently. The child's love for, or fear of, the abuser might encourage acceptance of behaviours that the mother considers abusive rather than disciplinary. Some observed differences were attributed to stronger family ties, more stable relations, adherence to religious laws and lower alcoholism prevalent in a traditional community such as is found in Upper Egypt.
When we compare the rates for Egyptian preschool children, primary-school children and our students, it appears that sexual abuse may increase with age $(0 \%$, $2.3 \%$ and $7 \%$ respectively) while physical abuse may decrease with age $(78.8 \%$, $24.4 \%$ and $7.6 \%$ respectively) $[18,21]$. This observation has an important implication in that age should be considered in planning intervention against abuse. The occurrence of combined forms of abuse indicates interaction between the 3 types. When 1 form is encountered, it is advisable to look for others.

\section{Risk factors in child abuse}

Child abuse is a problem with deleterious effects that last into adulthood. In some nations the price tag for helping and protecting abused children is staggering. The cost in the United States of America is more than US\$ 94 thousand million every year or US\$ 258 million per day [29]. Preventive efforts should target specific risk factors that vary with geographical and cultural settings. In our Egyptian community, abuse was associated with many child, parental, familial, socioeconomic and school factors.

\section{Child risk factors}

Child factors that were associated with abuse in univariate analysis were sex, perception of a child as helpless or hyperactive, presence of sickness, disability, wasting or learning difficulty, living away from the family for some time and sharing a bed with others. The sex of the child was an important risk factor only for sexual abuse as males were more exposed than females. This contradicts studies from the United States and might be attributed to the relative freedom male children in Egyptian society enjoy in travelling, staying out and mixing with all sorts of people compared

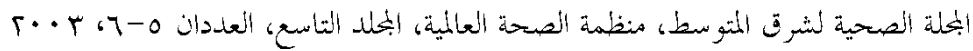


with their female counterparts $[10,30]$. The susceptibility of males to abusive acts from strangers was observed in a study in the USA in which strangers were responsible for $60 \%$ of male rapes or physical assaults [31]. Another possibility is that females are less likely to disclose abuse, especially sexual abuse. They may be less likely to share information with a stranger conducting a survey or even with medical doctors handling their cases [28].

Other studies have reported that handicapped and chronically ill children were at a much higher risk of abuse [23,32]. Chronically ill and handicapped children may be vulnerable because their already frustrated parents cannot accept further misbehaviours. Hostility directed to such children is not uncommon [32]. Wasting and having learning difficulties can be both a cause and an effect of abuse. Victims manifest disturbed sleep, appetite and eating habits that lead to decreased rates of growth and lower educational attainment [13,33]. A child with learning disabilities may be punis hed corporally and insulted by his family members and his teachers in an attempt to force improved performance.

In agreement with our findings, living away from the family and sharing a bed with others have been reported as risk factors in child abuse $[16,34,35]$. The former deprives the child of parental care, supervision, protection and love and exposes children to persons who may try to take advantage of them. The increased risks that accompany sharing of a bed with others are probably due to accidental stimulation and crowding [35].

Multivariate analysis of our data showed that children's characteristics were the most significant in predicting sexual abuse. Accordingly, hyperactive, disabled and wasted children and their families should be targeted in efforts to control sexual abuse.

\section{Parental risk factors}

In Egypt and elsewhere parental characteristics that have been reported as risk factors for abuse include young age, low education, occupation and illness $[4,18$, $26,36]$. Our results agreed regarding the effect of illness and occupation but not age or education. We found that the health status of parents had a significant effect on the occurrence of abuse. Maternal disease increased the odds of sexual and combined abuse significantly while paternal illness increased the odds of all but sexual abuse. This effect might be due to diminished care and supervision by the sick parent. Another possibility that has been suggested is that when a father has an unsatisfactory relationship with his ill wife, he might feel justified abusing his daughter [37].

Although occupation did not significantly affect overall abuse, children of mothers who work outside the home were at higher risk of emotional abuse than those of housewives. Usually, abused children of mothers who work outside the home were abused by someone other than the mother. In a South African study, 'mother employed and not as labourer' and 'violence at home not seldom' were 2 of 4 factors significantly increasing the likelihood of child sexual abuse [15].

Young and immature parents have been reported to be more abusive than older ones $[18,36]$. The primary factor in child maltreatment in one study was parental age less than 20 years [36]. In our study, the mean age of both parents at childbirth was above 25 years. Illiteracy and low education were not associated with higher odds for abuse; rather, the odds were higher among partly educated and highly educated parents. The level of education was linked

$$
\text { المحلة الصحية لشرق المتوسط، منظمة الصحة العالمية، المخلد الثاسع، العددان 0-7، ب +. }
$$


to patterns of teaching, guiding, stimulating and communicating with children [38].

In Egypt, child education is a concern for most families, especially for educated parents. Educated parents demand high educational achievement from their children so as to increase the child's chances of being admitted to university. Unintentionally, this might cause the parents to become pushy, impulsive and punitive. Conduct disorders are often reported in association with academic failure and reading disability [39].

In addition to education, occupation and disease, other parental characteristics such as cruelty (severity or hardness), disinterest and prison record significantly increased the odds of abuse among Ihnasya adolescents. This has been observed elsewhere $[16,21]$. The absence of the father, which was highly prevalent $(21.1 \%)$ in the studied community, meant that less attention and supervision were paid to adolescents, rendering them victims of abuse. Furthermore, parental respect for children's needs, degree of parental care or negligence and parental attitude towards children's behaviour were predisposing factors for abusive behaviour and for the child to be a future abuser [21].

\section{Familial risk factors}

Among the fundamental risk factors for child abuse were disturbed family equilibrium, child-parent relationships and parents' marital relationships. The importance of the family setting as a protective factor for the wholesome development of the child has been reported and the loss of one or both parents, not living with both parents, not sharing social activities with them, parental addiction and alcoholism predisposes the child to abuse [16]. Other studies have emphasized the association with violence in the family, familial problems, separation and marital conflicts $[4,8,15]$.
Abuse in our study was significantly associated with parents' quarrels with adolescents, the presence of problems in the family, troubles between parents and smoking. Violence between parents predicted a higher level of mother-child punitiveness [40]. When parents have problems or are the victims of violence, they are more likely to have difficulty being emotionally available for their children. Substance abuse has been reported to increase all forms of child maltreatment through its interaction with socioeconomic stress and family dynamics [41].

The results of our study suggest that a large percentage of families handle things improperly. Parental knowledge of the principles of childrearing, especially in handling children with special needs (e.g. hyperactivity, illness or learning difficulties), seems to be deficient. Proper parental education about handling children with challenges is of utmost importance for raising them properly and would reduce the stresses on both parents and children.

\section{Socioeconomic factors}

Many researchers have reported the significant effects on abuse of low income, not belonging to nuclear families, living in congested surroundings and having a caregiver with experience of unskilled work or unemployment $[26,42]$. Contrary to their findings, abuse in our study was not significantly associated with income, property ownership or type of family. It was not associated with reading newspapers or watching TV. In our study, $24.6 \%$ of fathers and $12.9 \%$ of mothers could read and write only. Multivariate analysis showed that crowding was important in predicting emotional abuse. With large numbers of children, a parent's ability to care may be lessened. Children in the largest families were physically neglected at 3 times the

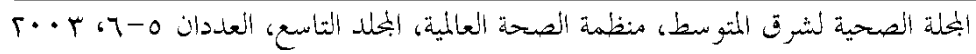


rate of those who came from single-child families [10].

The observed discrepancies regarding risk factors between our study and others, namely education and socioeconomic factors, reflect to a great extent variability in geographic region, culture and childrearing practices. They capture what is expected from a child by the caregiver, how the latter responds to non-conformance and the perception of both to an encounter. For example, one Egyptian study used reluctance of the mother to consult the school when there had been a complaint about a child's academic progress to indicate educational negligence [26]. A parent might not be reluctant to contact the school but might also respond improperly through criticism, nervousness or threatening, which are emotionally abusive to the children [22].

\section{School factors}

Large proportions of the emotionally and combined abused children $(49.3 \%$ and $44.2 \%$ ) reported being maltreated by teachers. This maltreatment was significantly associated with the presence of educational difficulties and the perception of a child as helpless, having a disability or having a somatic disease. Unfortunately, instead of receiving more attention and care, children with learning difficulties, disabilities or somatic diseases were more susceptible to teacher maltreatment and abuse. Teachers are often responsible for abuse; they should be educated and supported to address the problem [4]. In a 1998 study, some professionals working with children, such as social workers and school physicians, were deficient in their knowledge of child abuse [25].

\section{Sequelae}

Because physical and sexual abuse are the most commonly reported types of abuse, their sequelae have been studied thoroughly. In a brief review of the literature concerning the impact of sexual abuse on the victim's psychological well-being, abused children suffered from depression, anger, hostility and self-destructive behaviours [43]. Children who experienced violence either as victims or as witnesses were at increased risk of becoming violent themselves [44]. Those findings were confirmed in our study in that abused children had higher odds for developing violent behaviours. Perhaps as a reaction to neglect, a large percentage (40\%) of abused children in our study practised behaviours to attract the attention of parents including beating siblings, committing intentional mistakes in front of parents and embarrassing parents in front of others, or developed habits such as smoking or drinking alcohol (10\%).

Another even graver sequel of abuse is the development of abusive behaviour [21]. In a 1999 study in Egypt, abused children exhibited deviant behaviour in the form of aggression or inappropriate sexual behaviour [39]. Our findings were similar in Ihnasya where the odds of sexual behaviours such as staring at or touching the genitalia of the same or other sex were significantly raised by abuse. Not only were children subject to such immediate sequelae but long-term effects have also been reported [5-7]. Sexual abuse during childhood correlated significantly with marital problems and disorders of adult personality and behaviour, especially disorders associated with sexual development and orientation $[43,45]$. Moreover, histories of abuse were positive in patients with neurotic, psychiatric or stress-related disorders and those with substance abuse [46].

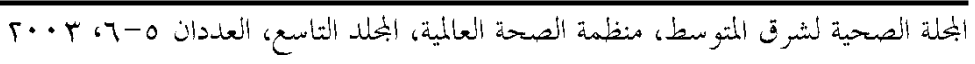




\section{Conclusions}

The prevalence of abuse was higher among adolescents in our study than among younger children in two previous studies [4,21]. Many child, parental and sociofamilial factors were involved. The significant predictors of emotional abuse were degree of crowding in the home, sickness and teacher maltreatment. Predictors of physical abuse were maternal disinterest, maternal education and signs of injury. Sexual abuse was significantly predicted by a child being hyperactive, disabled, having a disinterested mother, of low birth order or wasting. Abuse has serious outcomes in the form of violence, smoking and development of abusive behaviour. Our study indicated that perhaps neither parents nor schoolteachers knew how to deal with children with special needs. Accordingly we need to increase the awareness of parents, teachers, medical and paramedical person- nel and the general public about the problem, its magnitude, manifestations, prevention and management. Family equilibrium and strong parent-child relationships are important for child safety. Accordingly, family-counselling services should be available and parents with problems should be encouraged to use them. The use of rewards rather than punishments should be encouraged among parents and others working with children. Children must be taught at school and through the media how to defend themselves and how to behave when faced with threats of abuse. Social and psychiatric services need support both in primary health care and school settings. The establishment of governmental and nongovernmental organizations and groups to combat abuse need to be encouraged. Electronic journals and networks developed by international organizations should be used.

\section{References}

1. Hopper J. Child abuse: Statistics, research and resources, 2001 (http:// www.jimhopper.com/abstats/, accessed 26 May 2004).

2. Nelson WE, Behrman RE, Vaughan VC. Child abuse and neglect. In: Behrman RE et al., eds. Nelson textbook of pediatrics, 3rd ed. Philadelphia, WB Saunders Company, 1986:79-84.

3. Singh H. Textbook of paediatric nursing. New Delhi, India, Interprint, 1996:233.

4. Abdel-Qader AA. Child abuse and neglect among school children in Banha. Medical and psychiatric study [thesis]. Banha, Egypt, Zagazig University, 1985.

5. Taylor RR, Jason LA. Sexual abuse, physical abuse, chronic fatigue, and chronic fatigue syndrome: a community based study. Journal of nervous and mental disease, 2001, 189(10):709-15.

6. Molnar BE, Berkman LF, Buka SL. Psychopathology, childhood sexual abuse and other childhood adversities: relative links to subsequent suicidal behaviour in the US. Psychological medicine, 2001, 31(6):965-77.

7. Herrera VM, McCloskey LA. Gender difference in the risk for delinquency among youth exposed to family violence. Child abuse \& neglect, 2001, 25(8): 1037-51.

8. Abel-Baqi OM et al. Risk factors and concurrent psychiatric morbidity of 'child abuse' in an Egyptian sample. Ain

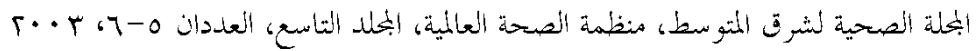


Shams medical journal, 1993, 44(79):565-70.

9. El-Shennawi EE, Abdel-Salam HFA, Fouad AA. Diagnostic markers of physically abused children in autopsy cases. Mansoura journal of forensic medicine and clinical toxicology, 1996, 4(1):7386.

10. Sedlak AJ, Broadhurst DD. Executive summary of the third national incidence study of child abuse and neglect. Washington, DC, National Centre on Child Abuse and Neglect, US Department of Health and Human Services, September 1996.

11. Child maltreatment 1999: Reports from the States to the National Child Abuse and Neglect Data System. Washington, DC, Administration for Children and Families, US Department of Health and Human Services, 1999 (http://www.acf. dhhs.gov/programs/cb/publications/ cm99/index.htm, accessed 26 May 2004).

12. Trocmé $\mathrm{N}$ et al. Canadian incidence study of reported child abuse and neglect. Final report. Ottawa, Ministry of Public Works and Government Services, 2001 (http://www.hc-sc.gc.ca/pphbdgspsp/publicat/cisfr-ecirf/index.html, accessed 26 May 2004).

13. Meadow R. ABC of child abuse, 3rd ed. London, British medical journal books, 1997.

14. Speight MA. Child abuse and neglect within the family. In: Jeliffe DB et al., eds. Diseases of children in tropics and subtropics, 4th ed. London, Edward Arnold Publishers Ltd., 1991.

15. Madu SN, Peltzer K. Risk factors and child sexual abuse among secondary school students in Northern Province (South Africa). Child abuse \& neglect, 2000, 24(2):259-68.
16. Benjamin $\mathrm{G}$ et al. Risk factors for child abuse in Dominica, 2001 (http://www. uwichill.edu.bb/bnccde/dominica/ conference/papers/Benjamin.html, accessed 26 May 2004).

17. Bader SH. Ocular manifestations of child abuse. Bulletin of the Ophthalmological Society of Egypt, 1988-1991, 84:35761.

18. Wali WF et al. Child abuse at preschool age. New Egyptian journal of medicine, 1993, 9(3):810-5.

19. Radhwan SA et al. Study of the factors causing child abuse and related health disorders. The impact of medical sciences on planning of modern Egypt, International Annual Ain Shams Medical Congress, Cairo, 16-19 March 1998.

20. Abdel-Rahman AE. Retrospective and prospective study of child abuse cases [thesis]. Cairo, Ain Shams University, 1994.

21. Abdel-Rahman S, Nashed ER. Psychiatric aspects of child abuse in Egypt. Egyptian journal of psychiatry, 1994, 17(2): 137-45.

22. Shara HM. Assessment of child abuse among students of selected primary governmental schools in Cairo [thesis]. Cairo, Cairo University, 1999.

23. Child abuse and neglect in California. Sacramento, California, Legislative Analyst's Office, State of California, 1996.

24. World Health Organization Working Group. Use and interpretation of anthropometric indicators of nutritional status. Bulletin of the World Health Organization, 1986, 64:929-41.

25. Youssef RM, Atta HY. Child abuse and neglect: its perception by those who work with the children. Eastern Mediter- 
ranean health journal, 1998, 4(2):27692.

26. Atta HY, Youssef RM. Child abuse and neglect: mothers' behaviour and perceptions. Eastern Mediterranean health journal, 1998, 4(3):502-12.

27. Barker P, Barker P. Basic child psychiatry, 5th ed. Oxford, Blackwell Scientific, 1988.

28. Mazza D, Dennerstein L, Ryan V. Physical, sexual and emotional violence against women: a general practicebased prevalence study. Medical journal of Australia, 1996, 164(1):14-7.

29. Fromm S. Total estimated cost of child abuse and neglect in the United States: statistical evidence. Chicago, Illinois, National Center on Child Abuse Prevention Research, 2001 (http://www. preventchildabuse.org/learn_more/ research_docs/cost_analysis.pdf, accessed 26 May 2004).

30. Anderson $\mathrm{J}$ et al. Prevalence of childhood sexual abuse experience in a community sample of women. Journal of the American Academy of Child and Adolescent Psychiatry, 1993, 32:911-9.

31. Tijaden P, Thoennes N. Prevalence, incidence and consequences of violence against women: findings from the $\mathrm{Na}$ tional Violence Against Women Survey. Washington DC, National Institute of Justice, and Atlanta, Georgia, Centers for Disease Control and Prevention, 1998.

32. Walker LS, Garber J, Van Slyke DA. Do parents excuse the misbehavior of the children with physical and emotional symptoms? An investigation of the pediatric sick role. Journal of pediatric psychology, 1995, 20(3):329-45.

33. Osofsky JD. Addressing youth victimization. Washington, DC, Office of Juvenile Justice and Delinquency Prevention, US
Department of Justice, 2001 (http:// w w w.ncjrs.org/htm I/ojjdp/ action plan update 2001 10/ index.html, accessed 26 May 2004).

34. Flanagan CA. Change in family work status: effects on parent-adolescent decision making. Child development, 1990, 61:163-77.

35. Sumba RO, Bwibo NO. Child battering in Nairobi, Kenya. East African medical journal, 1993, 70(11):688-92.

36. Sidebotham $P$ et al. Avon Longitudinal Study of Parents and Children. Child maltreatment in the 'children of the nineties': a longitudinal study of parental risk factors. Child abuse \& neglect, 2001, 25(9):1177-200.

37. Trusedell D, Deschner J, McNeil J. Incidence of wife abuse in incestuous families. Social work journal, 1986, 31(2): 138-40.

38. Herrenkohl EC et al. Risk factors for behavioral dysfunction: the relative impact of maltreatment, SES, physical health problems, cognitive ability, and quality of parent-child interaction. Child abuse \& neglect, 1995, 19(2):191-203.

39. Saif MA. Deviant behaviour in children [thesis]. Cairo, Ain Shams University, 1999.

40. Miller BA, Smyth NJ, Mudar PJ. Mothers' alcohol and other drug problems and their punitiveness toward their children. Journal of studies on alcohol, 1999, 60(5):632-42.

41. Sheridan MJ. A proposed intergenerational model of substance abuse. Family functioning and abuse/neglect. Child abuse \& neglect, 1995, 19(5):51930.

42. Isaranurug $S$ et al. Factors relating to the aggressive behaviour of primary caregiver toward a child. Journal of the Medi-

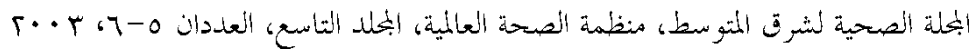


cal Association of Thailand, 2001, 84(10):1481-9.

43. Foss $M$. The calculation of damages in sexual abuse cases. The expert witness newsletter, 1999, 4(3) (http://www. economica.ca/ew43p1.htm, accessed 26 May 2004).

44. Marans S, Berkman JD. Child development-community policing: partnership in a climate of violence. Washington DC, Office of Juvenile Justice and Delin- quency Prevention, US Department of Justice, March 1997.

45. Sayed YH, Ali S, El-Bakery A. Late psychiatric sequelae of childhood sexual abuse [thesis]. Cairo, Cairo University, 1998.

46. Gil-Rivas $V$ et al. Sexual and physical abuse: do they compromise drug treatment outcomes? Journal of substance abuse treatment, 1997, 14(4):351-8.

\section{Child and Adolescent Mental Health Initiatives of the Department of Mental Health and Substance Abuse}

For the past two years the Department has supported the development of a coordinated child and adolescent mental health programme. The programme has fostered a recognition throughout WHO and in the WHO Regions that child and adolescent mental health is a necessary priority for the healthy development of societies. WHO's Department of Mental Health and Substance Abuse has initiated three programmes which together form a coordinated effort to address global child and adolescent mental health problems. The programme at its very core appreciates the global interdependence of societies. The three programme elements include 1) a campaign on the stigma associated with mental illness among youth, 2) a global policy initiative that will equip ministries of health to develop coordinated, responsive programmes where child and adolescent mental health will be integrated into overall health care, and 3) a programme to assess the global treatment gap associated with mental illness. Further information can be obtained on line at: http:/ /www.who.int/mental_health/prevention/childado/en/ 